\title{
Breast and ovarian cancer penetrance of BRCA1/2 mutations among Hong Kong women
}

\author{
LingJiao Zhang ${ }^{1, *}$, Vivian Y. Shin ${ }^{2, *}$, Xinglei Chai ${ }^{1}$, Alan Zhang ${ }^{3}$, Tsun L. Chan ${ }^{4,5}$, \\ Edmond S. Ma ${ }^{4,5}$, Timothy R. Rebbeck ${ }^{6}$, Jinbo Chen ${ }^{1}$ and Ava Kwong ${ }^{2,5,7}$ \\ ${ }^{1}$ Department of Biostatistics, Epidemiology, and Informatics, University of Pennsylvania Perelman School of Medicine, \\ Philadelphia, PA, USA \\ ${ }^{2}$ Department of Surgery, the University of Hong Kong, Hong Kong \\ ${ }^{3}$ Sidwell High School, Bethesda, MD, USA \\ ${ }^{4}$ Department of Molecular Pathology, Hong Kong Sanatorium \& Hospital, Hong Kong \\ ${ }^{5}$ Hong Kong Hereditary Breast Cancer Family Registry, Hong Kong \\ ${ }^{6}$ Dana Farber Cancer Institute and Harvard TH Chan School of Public Health, Boston, MA, USA \\ ${ }^{7}$ Department of Surgery, Hong Kong Sanatorium \& Hospital, Hong Kong \\ *These authors have contributed equally to this work \\ Correspondence to: Ava Kwong, email: avakwong@hku.hk \\ Jinbo Chen, email: jinboche@mail.med.upenn.edu
}

Keywords: BRCA 1; BRCA2; breast and ovarian cancer; penetrance; Chinese population

Received: November 16, 2017 Accepted: January 03, 2018 Epub: February 02, 2018 Published: May 18, 2018

Copyright: Zhang et al. This is an open-access article distributed under the terms of the Creative Commons Attribution License 3.0 (CC BY 3.0), which permits unrestricted use, distribution, and reproduction in any medium, provided the original author and source are credited.

\section{ABSTRACT}

Germline mutations in BRCA1 and BRCA2 (BRCA1/2) are associated with increased risk of breast and ovarian cancer. The penetrance of breast and ovarian cancer in BRCA1/2 mutation carriers has been well characterized in Caucasian but not in Asian. Two studies have investigated the breast cancer risk in Asian women with BRCA1/2 mutations, and no published estimates are available for ovarian cancer. Therefore, we estimated the age-specific cumulative risk of BRCA1/2-associated breast and ovarian cancer in Chinese women. From Jan 2007 to Nov 2015, the Hong Kong Hereditary Breast Cancer Family Registry identified 1635 families with hereditary breast-ovarian cancer. Among probands in these families, 66 had BRCA1 mutations, 84 had BRCA2 mutations, and 1,485 tested negative for BRCA1/2 mutations. Using the female firstdegree relatives of these probands, we estimated the risk of breast and ovarian cancer using a modified marginal likelihood approach. Estimates of breast cancer penetrance by age 70 were $53.7 \%$ ( $95 \%$ CI $34.5-71.6 \%)$ for BRCA1 mutation carriers and $48.3 \%$ (95\% CI 31.8-68.5\%) for BRCA2. The estimated risk of ovarian cancer by age 70 was $\mathbf{2 1 . 5 \%}$ and $\mathbf{7 . 3 \%}$ for Chinese women carrying BRCA1 or BRCA2 mutation respectively. A meta-analysis of available studies in Asian women revealed pooled estimates of breast cancer risk by age 70 of $44.8 \%$ (95\% CI 33-57.2\%) and $40.7 \%$ (95\% CI 31.3-50.9\%) for $B R C A 1$ and $B R C A 2$ mutation carriers respectively. These data suggest that BRCA1/2associated breast cancer risk for Chinese women is similar to that for Caucasian women, although BRCA1/2-associated ovarian cancer risks are lower for Chinese women.

\section{INTRODUCTION}

$B R C A 1$ and $B R C A 2(B R C A 1 / 2)$ are human tumor suppressor genes which play a role in DNA damage repair and transcriptional regulation [1]. Germline mutations in $B R C A 1 / 2$ are associated with an increased risk and early age onset for hereditary breast and ovarian cancer [2]. Genetic counseling is now routinely offered to individuals 
Table 1: Number and age at diagnosis of breast and ovarian cancer cases in $B R C A 1, B R C A 2$, and non-carrier probands and first-degree relatives

\begin{tabular}{|c|c|c|c|c|c|c|}
\hline & $\begin{array}{c}\text { No. breast } \\
\text { cancer }\end{array}$ & $\begin{array}{c}\text { Age at } \\
\text { diagnosis }\end{array}$ & $\begin{array}{c}\text { Age at } \\
\text { diagnosis }\end{array}$ & $\begin{array}{c}\text { No. ovarian } \\
\text { cancer }\end{array}$ & $\begin{array}{c}\text { Age at } \\
\text { diagnosis }\end{array}$ & $\begin{array}{c}\text { Age at } \\
\text { diagnosis }\end{array}$ \\
\hline & No. $(\%)$ & Mean (SE) & Median (IQR) & No. $(\%)$ & Mean (SE) & Median (IQR) \\
\hline \multicolumn{7}{|l|}{ Probands } \\
\hline BRCA1 & $58(87.9)$ & $41.8(1.2)$ & $40(35-48)$ & $17(25.8)$ & $47.1(2.0)$ & $45(41-52)$ \\
\hline$B R C A 2$ & $83(98.8)$ & $43.4(0.9)$ & $42(37-49)$ & $4(4.8)$ & $46.5(0.9)$ & $46(45.5-47.5)$ \\
\hline Non-carrier & $1457(98.1)$ & $44.8(0.3)$ & $44(38-50)$ & $35(2.4)$ & $40.6(1.9)$ & $43(33-49)$ \\
\hline \multicolumn{7}{|l|}{$\begin{array}{l}\text { First-Degree } \\
\text { Relatives with } \\
\text { known } B R C A \\
\text { status }\end{array}$} \\
\hline$B R C A 1$ & $49(21.3)$ & $45.1(1.8)$ & $42(36-53)$ & $20(8.7)$ & $50.4(1.6)$ & $50(45-55)$ \\
\hline$B R C A 2$ & $63(20.4)$ & $45.8(1.5)$ & $45(38-50)$ & $5(1.6)$ & $66.0(4.8)$ & $62(61-69)$ \\
\hline Non-carrier & $456(8.4)$ & $51.1(0.5)$ & $50(44-58)$ & $42(0.8)$ & $49.0(2.4)$ & $49(35-60)$ \\
\hline
\end{tabular}

IQR: Interquartile range.

with high-risk of carrying a $B R C A 1$ or $B R C A 2$ mutation. Correspondingly, personalized prevention strategies will be offered according to their risk level, which is often assessed through a risk prediction model. Thus, risk assessment in BRCA1/2 mutation carriers is of great importance in clinical service and cancer management.

The risk estimates of breast and ovarian cancer in $B R C A 1 / 2$ mutation carriers have been well characterized for Caucasian women and individuals of AshkenaziJewish background [2-4]. According to the most recent meta-analysis, the cumulative breast cancer risk by age 70 years was estimated to be $55 \%$ (95\% CI: $50-59 \%$ ) and 47\% (95\% CI: 42-51\%) for Caucasian women carrying a $B R C A 1$ or $B R C A 2$ mutation respectively. The estimates of ovarian cancer penetrance by age 70 were $39 \%$ (95\% CI: $34-45 \%)$ for $B R C A 1$ mutation carriers and $17 \%$ (95\% CI: 13-21\%) for BRCA2 mutation carriers. Since the mutation frequency and cancer incidence vary by ethnic groups $[5,6]$, these estimates cannot be extrapolated to a large outbred population such as East Asia.

The contribution of $B R C A 1$ and $B R C A 2$ mutations to breast and ovarian cancer incidence has not been well explored in Asian population, where both cancer incidence and mutation prevalence are lower compared to western countries $[7,8]$. So far only two studies have investigated breast cancer risk in Asian women with $B R C A 1 / 2$ mutations. Yao et al. identified $70 B R C A 1$ and $55 B R C A 2$ mutation-carrying families from 1,816 unselected Chinese women with breast cancer, and estimated the breast cancer risk by age 70 as $37.9 \%$ (95\% CI: $24.1-54.4 \%$ ) for $B R C A 1$ and $36.5 \%$ (95\% CI: 26.7-51.8\%) for BRCA2 using a kincohort design [9]. Park et al. reported their estimates for
Korean women based on 151 BRCA1 and 225 BRCA2 mutation-carrying families using a modified segregation analysis [10]. According to their study, Korean women with $B R C A 1$ mutation had a cumulative risk of $49 \%(95 \%$ CI: $11-98 \%$ ) for development of breast cancer by age 70 , and the risk was $35 \%$ (95\% CI: $16-65 \%)$ for $B R C A 2$. However, there is no published ovarian cancer estimates associated with these mutations in Asian women.

The aim of our study is to estimate breast and ovarian cancer risk in Chinese female BRCA1/2 mutation carriers using a more efficient method based on a relatively large study population. We will also conduct a meta-analysis to integrate available estimates of breast cancer risk in Asian women carrying a $B R C A 1$ or $B R C A 2$ germline mutation into a consensus estimate of penetrance.

\section{RESULTS}

A total of $66 B R C A 1,84 B R C A 2$, and 1,485 mutation-negative families were included in our study. The mutation frequencies in this sample of high-risk families for $B R C A 1$ and $B R C A 2$ were estimated as $2.1 \%$ and $2.7 \%$ respectively. Data for the 5,949 first-degree relatives was utilized to obtain estimates of breast cancer penetrance in mutation carriers (230 from BRCA1 carrier relatives, 309 from $B R C A 2$ carrier relatives and 5,410 from non-carrier relatives). Although most of the first-degree relatives were un-genotyped $(67.4 \%, 73.1 \%$, and $99.6 \%$ for $B R C A 1$, $B R C A 2$ and non-carrier relatives respectively), $16.1 \%$ and $14.6 \%$ of first-degree relatives were confirmed mutation carriers for $B R C A 1$ and $B R C A 2$ relatives respectively, and $16.5 \%$ and $12.3 \%$ were confirmed non-carriers. 
Table 2: Age-specific penetrance of breast cancer $(\times 100)$ by $B R C A 1$ and $B R C A 2$ mutation status, estimated using data from the first-degree relatives by the modified kin-cohort method

\begin{tabular}{lccc}
\hline & BRCA1 carrier & BRCA2 carrier & Non-carrier \\
\hline Age Interval & Penetrance (95\% CI) & Penetrance (\%) (95\% CI) & Penetrance (\%) (95\% CI) \\
\hline 20-40 years & $10.0(4.7-15.7)$ & $6.7(3.2-11.0)$ & $1.1(0.8-1.5)$ \\
20-50 years & $16.3(8.6-25.0)$ & $21.1(12.3-31.1)$ & $6.3(5.4-7.2)$ \\
20-60 years & $30.5(18.0-46.6)$ & $31.4(21.6-42.6)$ & $11.8(10.5-13.0)$ \\
20-70 years & $53.7(34.5-71.6)$ & $48.3(31.8-68.5)$ & $16.1(14.3-17.8)$ \\
\hline
\end{tabular}

\section{Risk of breast cancer in first-degree relatives}

A total of 568 breast cancer cases occurred in first-degree relatives, with an incidence of $21.3 \%, 20.4$, and $8.4 \%$ for BRCA1, BRCA2 and non-carrier families, respectively (Table 1). The risk of breast cancer in the first-degree relatives of $B R C A 1$ and $B R C A 2$ probands was significantly higher than in first-degree relatives of non-carrier families (hazard ratio, $\mathrm{HR}=3.31,95 \%$ CI 2.46 4.44, $p<0.001$; $\mathrm{HR}=3.31,95 \%$ CI $2.46-4.44, p<0.001$ for $B R C A 1$ and $B R C A 2$ respectively). For probands, the mean age at diagnosis of breast cancer in $B R C A 1$ carriers was significantly earlier than non-carrier (41.8 vs 44.8 years, $p=0.02$ ). There was no significant difference in age at diagnosis between $B R C A 1$ and $B R C A 2$ carrier families (41.8 vs 43.4 years, $p=0.28$ ) nor $B R C A 2$ carrier families and non-carrier families (43.4 vs 44.8 years, $p=0.22$ ). The results were similar for the first-degree relatives. The mean age at diagnosis in first-degree relatives of $B R C A 1$ carriers or $B R C A 2$ carriers was significantly earlier than that of non-carrier families (45.1 vs 51.1 years, $\mathrm{p}=0.0005$;
45.8 vs 51.1 years, $\mathrm{p}=0.0005)$. There was no significant difference between $B R C A 1$ and $B R C A 2$ families (45.1 vs 45.8 years, $\mathrm{p}=0.76$ ).

\section{Age-specific penetrance of breast cancer in mutation carriers}

The estimated penetrance of breast cancer in $B R C A 1$ mutation carriers by age 70 years was $53.7 \%$ (95\% CI: $34.5-71.6 \%$ ) (Table 2 \& Figure 1), which is higher than that for Korean women reported by Park et al., 49\% (95\% CI: 11-98\%) [10], and for Chinese women reported by Yao et al., 37.9\% (95\% CI: 24.1-54.4\%) [9]. Estimates by age $40,50,60,70$ years from all three studies were shown in Table 3. The meta-analytic estimate of penetrance by age 70 years based on these three studies was $44.8 \%$ (95\% CI: 33-57.2\%) (Test for heterogeneity: $\mathrm{p}=0.49)$. The metaanalytic estimates were $5.2 \%$ (95\% CI: 1.3-18.2\%), $13.6 \%$ (95\% CI: $8.9-20.3 \%$ ), and $30.9 \%$ (95\% CI: $21.5-42.2 \%$ ) for age intervals 20 to 40,20 to 50 , and 20 to 60 years, respectively.
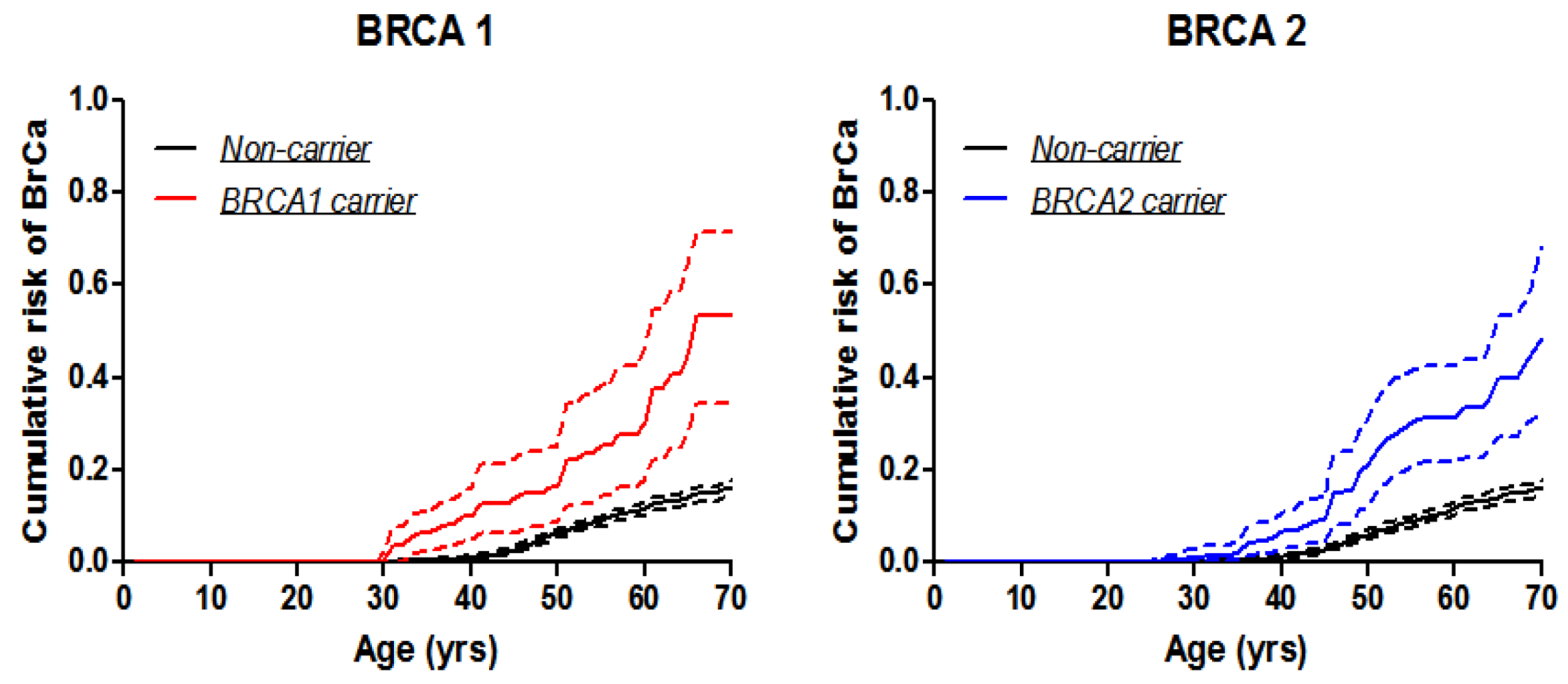

Figure 1: Breast cancer penetrance estimates by the modified kin-cohort method using data from first-degree relatives of probands who carry BRCA1 or BRCA2 mutations from Hong Kong Hereditary and High Risk Breast Cancer Programme. 
Table 3: Meta-analytic estimates of breast cancer penetrance $(\times 100)$ in Asian women who carry $B R C A 1$ or $B R C A 2$ mutations

\begin{tabular}{lcccc}
\hline Study & Korea & Beijing & Hong Kong & Meta-analytic Estimates \\
\hline Age Interval & $\begin{array}{c}\text { Penetrance } \mathbf{( \% )} \\
\mathbf{( 9 5 \%} \mathbf{C I})\end{array}$ & $\begin{array}{c}\text { Penetrance } \mathbf{( \% )} \\
\mathbf{( 9 5 \%} \mathbf{C I})\end{array}$ & $\begin{array}{c}\text { Penetrance } \mathbf{( \% )} \\
\mathbf{( 9 5 \%} \mathbf{C I})\end{array}$ & $\begin{array}{c}\text { Penetrance } \mathbf{( \% )} \\
\mathbf{( 9 5 \%} \mathbf{C I})\end{array}$ \\
\hline $\boldsymbol{B R C A 1}$ & & & & \\
$20-40$ years & $10(2-45)$ & $2.2(0-4.4)$ & $10.0(4.7-15.7)$ & $5.2(1.3-18.2)$ \\
$20-50$ years & $27(5-84)$ & $9.9(3.3-17.2)$ & $16.3(8.6-25.0)$ & $13.6(8.9-20.3)$ \\
$20-60$ years & $41(9-95)$ & $29.3(17.6-47.1)$ & $30.5(18.0-46.6)$ & $30.9(21.5-42.2)$ \\
$20-70$ years & $49(11-98)$ & $37.9(24.1-54.4)$ & $53.7(34.5-71.6)$ & $44.8(33.0-57.2)$ \\
$\boldsymbol{B R C A 2}$ & & & & \\
$20-40$ years & $6(3-15)$ & $1.2(0-3.1)$ & $6.7(3.2-11.0)$ & $4.5(1.8-10.7)$ \\
$20-50$ years & $18(8-39)$ & $10.7(9.6-16.9)$ & $21.1(12.3-31.1)$ & $15.8(10.1-24.1)$ \\
$20-60$ years & $28(13-56)$ & $27.2(19.0-38.5)$ & $31.4(21.6-42.6)$ & $29.6(23.1-36.9)$ \\
$20-70$ years & $35(16-65)$ & $36.5(26.7-51.8)$ & $48.3(31.8-68.5)$ & $40.7(31.3-50.9)$ \\
\hline
\end{tabular}

Similarly, for $B R C A 2$ mutation carriers, the estimated penetrance of breast cancer by age 70 years was 48.3\% (95\% CI: 31.8-68.5\%) (Table 2 \& Figure 1), which is similar to Korean women, 35\% (95\% CI: $16-$ $65 \%)[10]$ and Chinese women in Beijing, 36.5\% (95\% CI: 26.7-51.8\%) [9] (Table 3). The meta-analytic estimate of penetrance by age 70 years based on these three studies was 40.7\% (95\% CI: 31.3-50.9\%) (Test for heterogeneity: $\mathrm{p}=0.16)$. The meta-analytic estimates were $4.5 \%(95 \%$ CI: $1.8-10.7 \%$ ), $15.8 \%$ (95\% CI: $10.1-24.1 \%$ ), and $29.6 \%$ (95\% CI: $23.1-36.9 \%$ ) for age intervals 20 to 40,20 to 50 , and 20 to 60 years, respectively.

\section{Age-specific penetrance for ovarian cancer}

The estimated penetrance of ovarian cancer by age 70 years was $21.5 \%$ (95\% CI: $10.4-37.0 \%)$ for $B R C A 1$ mutation carriers and $7.3 \%$ for $B R C A 2$ mutation carriers. The penetrance estimate by age 60 years was $13.7 \%$ (95\% CI 6.6-24.3\%) for BRCA1 mutation carriers and $1.3 \%$ for $B R C A 2$ mutation carriers (Table $4 \&$ Figure 2). The number of ovarian cancer cases among BRCA2 carriers was too small to permit reasonable estimation of confidence intervals.

\section{DISCUSSION}

BRCA1/2 mutations are known to increase the lifetime risk of breast cancer by $50-87 \%$ and ovarian cancer by $10-40 \%$, based on data derived primarily from Caucasians [2]. BRCA1/2 mutation carriers have been managed based on the existing guidelines such as NCCN guidelines. These guidelines include more intensive screening, risk-reducing surgeries such as mastectomy and salpingo-oopherectomy, and even the use of specific types of chemotherapy such as platinum agents or targeted therapy such as poly (ADP-ribose) polymerase (PARP) inhibitors $[15,16]$. Our current data revealed that the cumulative risks of ovarian cancer in Chinese is lower than that of the Caucasians, preventive surgery (e.g. salpingo-oopherectomy) maybe "overtreated" the patients or those healthy individuals who harbor the mutations. Hence, screening of germline BRCA1/2 mutations is crucial for appropriate clinical management of cancer risk, yet more studies on the prevalence and cumulative breast cancer risk for these genes in Asian women are warranted.

We reported the first large-scale estimate of BRCA1/2 prevalence in Southern Chinese families, ascertained through patients with triple negative breast cancer and those that had a family history of breast and/or ovarian cancers. These women have an elevated chance of carrying $B R C A 1 / 2$ mutations [11]. There was also a difference in the observed spectrum of mutations where over $40 \%$ of the $B R C A$ mutations were novel and had never been reported. We previously also collected data from a $B R C A$ consortium with 47 Asian countries and Asian population residing in North America on all the $B R C A$ mutations in breast cancer patients [17]. The prevalence of $B R C A$ mutations varies in different Asian cohorts, with $21.7 \%$ (BRCA1 9.3\%; BRCA2 12.4\%) in patients with family history of breast or ovarian cancer in Korea [18] and 17\% (BRCA1 11\%; BRCA2 6\%) in Malaysian patients with early onset of breast cancer [19]. In the present study, our Southern Chinese population had a higher $B R C A 1$ mutation than $B R C A 2$ mutation than in 
Table 4: Age-specific penetrance of ovarian cancer $(\times 100)$ by $B R C A 1$ and $B R C A 2$ mutation status, estimated using data from the first-degree relatives by the modified kin-cohort method

\begin{tabular}{lccc}
\hline & BRCA1 carrier & BRCA2 carrier & Non-carrier \\
\hline Age Interval & Penetrance (\%) (95\% CI) & Penetrance (\%) (95\% CI) & Penetrance (\%) (95\% CI) \\
\hline 30-50 years & $5.0(1.8-13.3)$ & - & $0.4(0.2-0.6)$ \\
30-60 years & $13.7(6.6-24.3)$ & $1.3^{1}$ & $0.7(0.4-1.0)$ \\
30-70 years & $21.5(10.4-37.1)$ & $7.3^{1}$ & $1.4(0.9-1.9)$ \\
\hline
\end{tabular}

${ }^{1}$ Number of events too small to allow for reasonable estimates of confidence intervals.

Mainland China (BRCA1 10.6\%; BRCA2 5.2\%), despite there were disparities in the selection criteria in each study [20]. In Hong Kong, the prevalence of $B R C A 1 / 2$ mutations was $9.4 \%$, and a slightly higher $B R C A 2$ mutation rate was observed [11]. Considering patients with triple-negative breast cancer, BRCA1 mutation dominancy was seen in both Asian and Caucasian populations [17].

It is important to know the estimated risk for women who carry $B R C A$ mutations, so that high risk patients can be identified for genetic screening and better surveillance options and treatment can be implemented in the genetic counseling. Risk prediction models such as BOADICEA, BRCAPRO and Myriad models are designed for the estimation of risk among women carrying a $B R C A$ mutation in hereditary breast cancers [21, 22]. These prediction tools have been developed based on different ethnic groups and with slight difference in predictive factors. Therefore, their performance needs to be validated for the selection of high risk patients [23, 24]. In view of this, we adopted the kin-cohort approach which treated the first-degree relatives of the probands as an ascertained cohort to the present study and modified the R kin. cohort package to improve the efficiency [13]. Meta-analytic penetrance estimates of BRCA1 and BRCA2 mutations in Asian carriers (results from three cohort studies) were $44.8 \%$ and $40.7 \%$ respectively. In general, Hong Kong has the highest estimated risk of breast cancer by age 70 years for both $B R C A 1$ and $B R C A 2$ carriers, but still much lower than that in Caucasians (40-87\% for BRCA1 and $27-84 \%$ for $B R C A 2)[25,26]$. The cumulative estimates of ovarian cancer in Caucasians ranged from $16-68 \%$ and $11-27 \%$ for $B R C A 1$ and $B R C A 2$ carriers respectively, which are in line with our findings that $B R C A 2$ carriers tend to have a lower risk of ovarian cancer $[25,26]$. The variability of these estimates can be influenced by other non-genetic and environmental factors (e.g. breast feeding, pregnancy and radiation exposure) [27].

To the best of our knowledge, this is the first study to report the penetrance of $B R C A$ mutation carriers in the Hong Kong Chinese population with breast and ovarian cancers, which differs from that in Caucasian populations. In this study, the ovarian cancer estimates was found to be different from that of the Caucasians. The cumulative estimates of breast cancer were similar, but the ethnicity-

\section{BRCA 1}

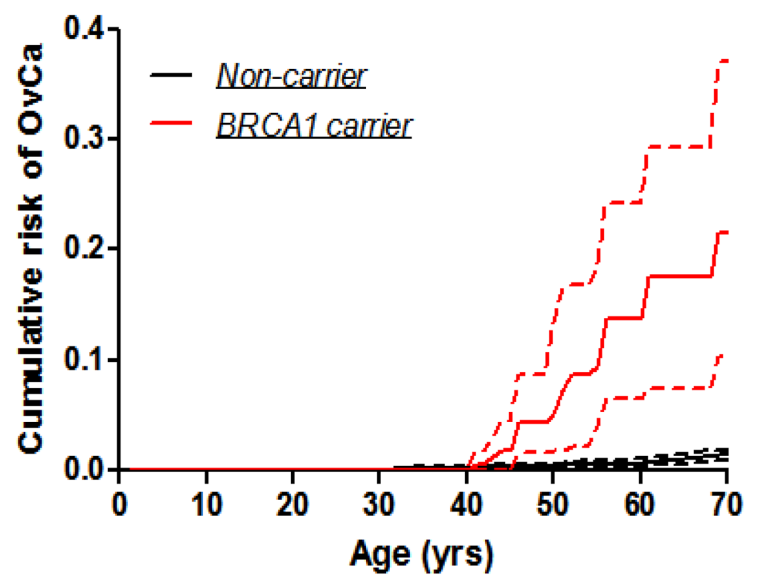

BRCA 2

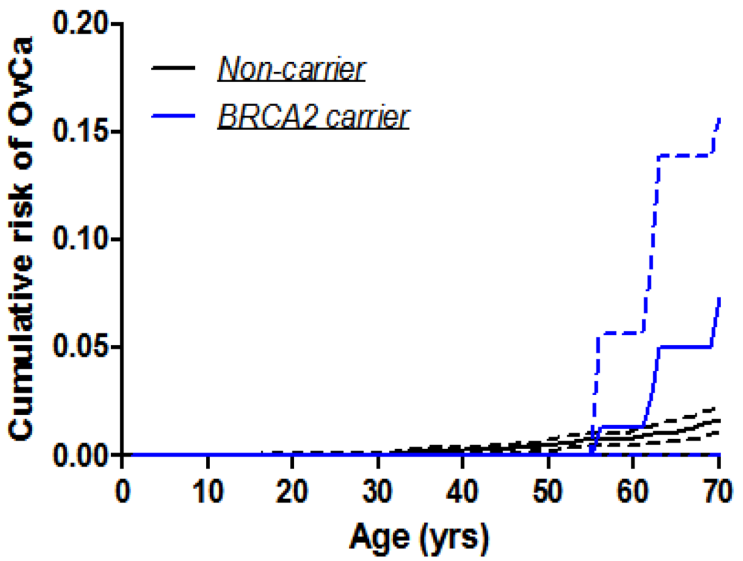

Figure 2: Ovarian cancer penetrance estimates by the modified kin-cohort method using data from first-degree relatives of probands who carry $B R C A 1$ or $B R C A 2$ mutations from Hong Kong Hereditary and High Risk Breast Cancer Programme. 
Table 5: Number of total and genotyped first degree relatives from the $66 B R C A 1$ families, $84 B R C A 2$ families, and 1485 non-carrier families

\begin{tabular}{|c|c|c|c|c|c|c|}
\hline & \multicolumn{2}{|c|}{ BRCA1 } & \multicolumn{2}{|c|}{ BRCA2 } & \multicolumn{2}{|c|}{ Non-carrier } \\
\hline & $\begin{array}{c}\text { Total } \\
\text { No. }(\%)\end{array}$ & $\begin{array}{c}\text { Per Family } \\
\text { Median No. } \\
\text { (IQR) }\end{array}$ & $\begin{array}{c}\text { Total } \\
\text { No. }(\%)\end{array}$ & $\begin{array}{l}\text { Per Family } \\
\text { Median No. } \\
\text { (IQR) }\end{array}$ & $\begin{array}{c}\text { Total } \\
\text { No. }(\%)\end{array}$ & $\begin{array}{c}\text { Per Family } \\
\text { Median No. } \\
\text { (IQR) }\end{array}$ \\
\hline First Degree Relatives & $230(77.7)$ & $3(2-4)$ & $309(78.6)$ & $3(2-4)$ & $5410(78.4)$ & $3(2-5)$ \\
\hline Mother & 66 (28.7) & $1(1-1)$ & $84(27.2)$ & $1(1-1)$ & $1485(27.4)$ & $1(1-1)$ \\
\hline Daughter & $37(16.1)$ & $0(0-1)$ & $48(15.5)$ & $0(0-1)$ & 967 (17.9) & $0(0-1)$ \\
\hline Sister & $127(55.2)$ & $1(1-3)$ & $177(57.3)$ & $2(1-3)$ & $2958(54.7)$ & $2(1-3)$ \\
\hline Carriers & $37(16.1)$ & $1(1-2)$ & $45(14.6)$ & $1(1-2)$ & $1(<0.1)$ & $0(0-0)$ \\
\hline Non-carriers & $38(16.5)$ & $0(0-1)$ & $38(12.3)$ & $0(0-1)$ & $19(0.4)$ & $1(1-1)$ \\
\hline Un-genotyped & $155(67.4)$ & $2(1-3)$ & $226(73.1)$ & $2(1-3)$ & $5390(99.6)$ & $3(2-5)$ \\
\hline
\end{tabular}

IQR: Interquartile range.

specific estimates are more relevant in terms of clinical management and surveillance. Hence, clinicians and genetic counselors need to be cautious when quoting cancer risk estimates from the Western data in explaining genetic test results to patients. Better understanding of the difference in penetrance and cancer risks would mean that present guidelines based on Western data may need to be modified to better suit ethnicities. Nevertheless, largescale multicenter studies in different regions of China will enhance the estimation of the overall cancer risk in $B R C A$ carriers with Chinese ethnicity. Genetic counseling and testing services are not a common practice in Mainland China and other Asian countries, except for Korea, mainly because of the limited access to qualified laboratory and healthcare professionals, and also resources for laboratory and clinical services are scanty [28]. Although genetic testing is very much standard care in the West, there is still limited resource to support testing and allow more popularized genetic testing in Asia. As more prevalence and spectrum data of Asian ethnicities emerges which is found to diverge from the West, estimated penetrance from larger cohort studies is needed to better guide patient care in these high-risk cohorts.

\section{MATERIALS AND METHODS}

\section{Ethics statement}

The study was performed in accordance with the Declaration of Helsinki. Written informed consent was obtained from all participants recruited in this study. This study was approved by the Institutional Review Board of the University of Hong Kong/Hospital Authority West Cluster and other contributing hospitals in Hong Kong (UW-16-274 T1299).

\section{Study participants}

In this study, a total of 1,635 Chinese families were recruited at the Hong Kong Hereditary Breast Cancer Family Registry from Jan 2007 to Nov 2015. The patient selection criteria were described previously [11]. A standard epidemiological questionnaire, including a detailed family history, was administered to patients and medical information, including pathology reports, was retrieved from the patient's medical records. Information from the epidemiological questionnaire included age at breast/ovarian cancer diagnosis, other cancers diagnosed in the patient, and a family history of breast, ovarian, and other cancers in first, second, and third degree relatives. Also, the date for preventive bilateral riskreducing salpingo-oophorectomy, bilateral risk-reducing mastectomy, last follow-up or death were collected. This cohort of families who were previously characterized by Sanger sequencing and 1,100 probands were subjected to NGS screening. Concurrent with sequencing, all patients were tested for large genomic rearrangement of BRCAI and $B R C A 2$ by multiplex ligation-dependent probe amplification (MLPA). Characteristics of patient cohorts were shown in Table 5.

All male relatives were excluded from the study due to gender difference in breast cancer penetrance. Only first degree relatives were included in the analysis due to lack of statistical methodology for incorporating distant relatives. Previous study showed that patients with triple negative breast cancer and those that had a family history of breast and/or ovarian cancers have increased risk of carrying BRCA1/2 mutations [11]. 66 female $B R C A 1$ carrier probands were identified, and age-at-onset data for 1,747 relatives were collected. 230 first-degree relatives were included in the analysis, with 66 mothers, 
37 daughters and 127 sisters (Supplementary Figure 1). Among the 230 first-degree relatives, 37 were confirmed BRCA1 mutation carriers, 38 non-carriers, and 155 were not tested.

Moreover, 84 female $B R C A 2$ carrier probands were recruited, with information on 2,330 relatives (1,145 male vs. 1,185 female) available. 309 female first-degree relatives, including 84 mothers, 48 daughters and 177 sisters, were included in the current analysis (Supplementary Figure 2). Of those, 45 were confirmed $B R C A 2$ mutation carriers, 38 non-carriers, and 226 were not tested. In addition, 1,485 non-carrier female probands provided information for 40,015 relatives. Of 5,410 firstdegree relatives (1,485 mothers, 967 daughters, 2,958 sisters), only 1 was $B R C A 2$ positive, 19 were $B R C A 1 / 2$ negative, and the rest were not tested (Supplementary Figure 3).

535 out of 7584 first degree relatives missed the time to event data $(21,22,492$ for BRCA1, BRCA2, negative proband respectively), and were excluded from the penetrance analysis. We then analyzed data from the remaining 5949 first degree relatives in the current study.

\section{Statistical analysis}

We analyzed the first-degree relatives of probands who were tested for BRCA1/2 mutations as a cohort, but corrected the bias due to the fact that the cohort was ascertained because probands had breast cancer. For breast cancer, the female first-degree relatives of the probands were followed from birth to the development of breast cancer (i.e., the primary event of interest), and were censored at the earliest date of ovarian cancer, preventive bilateral risk-reducing salpingo-oophorectomy, bilateral risk-reducing mastectomy, date of last follow-up, or death. For ovarian cancer, the follow-up was from birth to the development of ovarian cancer (i.e., the primary event of interest), or were censored at the earliest date of bilateral risk-reducing salpingo-oophorectomy, date of the last interview, or death. The age of diagnosis was compared across $B R C A 1, B R C A 2$, and non-carrier relatives using Student's $t$ test. To estimate age-specific penetrance of breast cancer in mutation carriers, we largely adopted a marginal likelihood approach for analyzing kin-cohort design where unavailable genotypes for the first-degree relatives were "imputed" from those of probands under Mendelian transmission [12]. We modified this approach to incorporate available genotypes for some of the first degree relatives to enhance statistical efficiency and implemented this modification using the $\mathrm{R}$ kin. cohort package (https://cran.r-project.org/web/packages/kin. cohort/index.html). This method requires an estimate of the frequencies of BRCA1/2 mutations, which we calculated as half the carrier frequency in the index family members [13]. The $95 \%$ confidence intervals were obtained through the bootstrapping method using families as units.

We also conducted meta-analysis to integrate estimates from our current study with published estimates from Beijing and Korea $[9,10]$ and summarized in Supplementary Table 1 . To date, the latter two were the only penetrance estimates available to date for breast cancer penetrance in $B R C A 1 / 2$ mutation carriers in Asian women. Heterogeneity between studies was assessed using the $\chi^{2}$ test. The pooled estimate as well as $95 \%$ confidence intervals was obtained using the DerSimonian and Laird method [14]. All analyses were conducted using software $\mathrm{R}$, and a test was considered statistically significant if a two-sided p-value was less than 0.05 .

\section{ACKNOWLEDGMENTS AND FUNDING}

This study was supported by grants from the Public Health Service (R01-CA164305 to LJZ, XLC and JBC; R01-CA83855 and R01-CA102776 to TRR), Health and Medical Research Fund (HK-03143406), Seed Fund for Basic Research (HKU-201511159129) and Hong Kong Hereditary Breast Cancer Family Registry. AK and JBC are independent of any commercial funder, had full access to all the data in the study and take responsibility for the integrity of the data and the accuracy of the data analysis.

\section{CONFLICTS OF INTEREST}

The authors declare no conflicts of interest.

\section{REFERENCES}

1. Jasin M. Homologous repair of DNA damage and tumorigenesis: the BRCA connection. Oncogene. 2002; 21: 8981-93. https://doi.org/10.1038/sj.onc.1206176.

2. Antoniou A, Pharoah PD, Narod S, Risch HA, Eyfjord JE, Hopper JL, Loman N, Olsson H, Johannsson O, Borg A, Pasini B, Radice P, Manoukian S, et al. Average risks of breast and ovarian cancer associated with BRCA1 or BRCA2 mutations detected in case Series unselected for family history: a combined analysis of 22 studies. Am J Hum Genet. 2003; 72: 1117-30. https://doi. org/10.1086/375033.

3. Gabai-Kapara E, Lahad A, Kaufman B, Friedman E, Segev S, Renbaum P, Beeri R, Gal M, Grinshpun-Cohen J, Djemal K, Mandell JB, Lee MK, Beller U, et al. Population-based screening for breast and ovarian cancer risk due to BRCA1 and BRCA2. Proc Natl Acad Sci U S A. 2014; 111: 14205 10. https://doi.org/10.1073/pnas.1415979111.

4. Struewing JP, Hartge P, Wacholder S, Baker SM, Berlin M, McAdams M, Timmerman MM, Brody LC, Tucker MA. The risk of cancer associated with specific mutations of BRCA1 and BRCA2 among Ashkenazi Jews. N Engl 
J Med. 1997; 336: 1401-8. https://doi.org/10.1056/ NEJM199705153362001.

5. John EM, Miron A, Gong G, Phipps AI, Felberg A, Li FP, West DW, Whittemore AS. Prevalence of pathogenic BRCA1 mutation carriers in 5 US racial/ethnic groups. JAMA. 2007; 298: 2869-76. https://doi.org/10.1001/ jama.298.24.2869.

6. Chen S, Parmigiani G. Meta-analysis of BRCA1 and BRCA2 penetrance. J Clin Oncol. 2007; 25: 1329-33. https://doi.org/10.1200/JCO.2006.09.1066.

7. Cao W, Wang X, Li JC. Hereditary breast cancer in the Han Chinese population. J Epidemiol. 2013; 23: 75-84.

8. Sharma P, Klemp JR, Kimler BF, Mahnken JD, Geier LJ, Khan QJ, Elia M, Connor CS, McGinness MK, Mammen JM, Wagner JL, Ward C, Ranallo L, et al. Germline BRCA mutation evaluation in a prospective triple-negative breast cancer registry: implications for hereditary breast and/or ovarian cancer syndrome testing. Breast Cancer Res Treat. 2014; 145: 707-14. https://doi.org/10.1007/ s10549-014-2980-0.

9. Yao L, Sun J, Zhang J, He Y, Ouyang T, Li J, Wang T, Fan Z, Fan T, Lin B, Xie Y. Breast cancer risk in Chinese women with BRCA1 or BRCA2 mutations. Breast Cancer Res Treat. 2016; 156: 441-5. https://doi.org/10.1007/ s10549-016-3766-3.

10. Park B, Dowty JG, Ahn C, Win AK, Kim SW, Lee MH, Lee JW, Kang E, Hopper JL, Park SK. Breast cancer risk for Korean women with germline mutations in BRCA1 and BRCA2. Breast Cancer Res Treat. 2015; 152: 659-65. https://doi.org/10.1007/s10549-015-3495-z.

11. Kwong A, Shin VY, Au CH, Law FB, Ho DN, Ip BK, Wong AT, Lau SS, To RM, Choy G, Ford JM, Ma ES, Chan TL. Detection of Germline Mutation in Hereditary Breast and/ or Ovarian Cancers by Next-Generation Sequencing on a Four-Gene Panel. J Mol Diagn. 2016; 18: 580-94. https:// doi.org/10.1016/j.jmoldx.2016.03.005.

12. Chatterjee N, Wacholder S. A marginal likelihood approach for estimating penetrance from kin-cohort designs. Biometrics. 2001; 57: 245-52.

13. Wacholder S, Hartge P, Struewing JP, Pee D, McAdams M, Brody L, Tucker M. The kin-cohort study for estimating penetrance. Am J Epidemiol. 1998; 148: 623-30.

14. DerSimonian R, Laird N. Meta-analysis in clinical trials. Control Clin Trials. 1986; 7: 177-88.

15. Kaufman B, Shapira-Frommer R, Schmutzler RK, Audeh MW, Friedlander M, Balmana J, Mitchell G, Fried G, Stemmer SM, Hubert A, Rosengarten O, Steiner M, Loman N, et al. Olaparib monotherapy in patients with advanced cancer and a germline BRCA1/2 mutation. J Clin Oncol. 2015; 33: 244-50. https://doi.org/10.1200/ JCO.2014.56.2728

16. Isakoff SJ, Mayer EL, He L, Traina TA, Carey LA, Krag KJ, Rugo HS, Liu MC, Stearns V, Come SE, Timms KM, Hartman AR, Borger DR, et al. TBCRC009: A Multicenter
Phase II Clinical Trial of Platinum Monotherapy With Biomarker Assessment in Metastatic Triple-Negative Breast Cancer. J Clin Oncol. 2015; 33: 1902-9. https://doi. org/10.1200/JCO.2014.57.6660.

17. Kwong A, Shin VY, Ho JC, Kang E, Nakamura S, Teo SH, Lee AS, Sng JH, Ginsburg OM, Kurian AW, Weitzel JN, Siu MT, Law FB, et al. Comprehensive spectrum of BRCA1 and BRCA2 deleterious mutations in breast cancer in Asian countries. J Med Genet. 2016; 53: 15-23. https:// doi.org/10.1136/jmedgenet-2015-103132.

18. Han SA, Kim SW, Kang E, Park SK, Ahn SH, Lee MH, Nam SJ, Han W, Bae YT, Kim HA, Cho YU, Chang MC, Paik NS, et al. The prevalence of BRCA mutations among familial breast cancer patients in Korea: results of the Korean Hereditary Breast Cancer study. Fam Cancer. 2013; 12: 75-81. https://doi.org/10.1007/s10689-012-9578-7.

19. Lee DS, Yoon SY, Looi LM, Kang P, Kang IN, Sivanandan K, Ariffin H, Thong MK, Chin KF, Mohd Taib NA, Yip $\mathrm{CH}$, Teo SH. Comparable frequency of BRCA1, BRCA2 and TP53 germline mutations in a multi-ethnic Asian cohort suggests TP53 screening should be offered together with BRCA1/2 screening to early-onset breast cancer patients. Breast Cancer Res. 2012; 14: R66. https://doi.org/10.1186/ bcr3172.

20. Kim YC, Zhao L, Zhang H, Huang Y, Cui J, Xiao F, Downs B, Wang SM. Prevalence and spectrum of BRCA germline variants in mainland Chinese familial breast and ovarian cancer patients. Oncotarget. 2016; 7: 9600-12. https://doi. org/10.18632/oncotarget.7144.

21. Antoniou AC, Pharoah PP, Smith P, Easton DF. The BOADICEA model of genetic susceptibility to breast and ovarian cancer. Br J Cancer. 2004; 91: 1580-90. https://doi. org/10.1038/sj.bjc.6602175.

22. Parmigiani G, Berry D, Aguilar O. Determining carrier probabilities for breast cancer-susceptibility genes BRCA1 and BRCA2. Am J Hum Genet. 1998; 62: 145-58.

23. Eoh KJ, Park JS, Park HS, Lee ST, Han J, Lee JY, Kim SW, Kim S, Kim YT, Nam EJ. BRCA1 and BRCA2 mutation predictions using the BRCAPRO and Myriad models in Korean ovarian cancer patients. Gynecol Oncol. 2017; 145: 137-41. https://doi.org/10.1016/j.ygyno.2017.01.026.

24. Kang E, Park SK, Lee JW, Kim Z, Noh WC, Jung Y, Yang JH, Jung SH, Kim SW. KOHBRA BRCA risk calculator (KOHCal): a model for predicting BRCA1 and BRCA2 mutations in Korean breast cancer patients. J Hum Genet. 2016; 61: 365-71. https://doi.org/10.1038/jhg.2015.164.

25. Milne RL, Antoniou AC. Modifiers of breast and ovarian cancer risks for BRCA1 and BRCA2 mutation carriers. Endocr Relat Cancer. 2016; 23: T69-84. https://doi. org/10.1530/ERC-16-0277.

26. Evans DG, Shenton A, Woodward E, Lalloo F, Howell A, Maher ER. Penetrance estimates for BRCA1 and BRCA2 based on genetic testing in a Clinical Cancer Genetics service setting: risks of breast/ovarian cancer quoted should 
reflect the cancer burden in the family. BMC Cancer. 2008; 8: 155. https://doi.org/10.1186/1471-2407-8-155.

27. Levy-Lahad E, Friedman E. Cancer risks among BRCA1 and BRCA2 mutation carriers. Br J Cancer. 2007; 96: 11-5. https://doi.org/10.1038/sj.bjc.6603535.

28. Nakamura S, Kwong A, Kim SW, Iau P, Patmasiriwat P, Dofitas R, Aryandono T, Hu Z, Huang CS, Ginsburg
O, Rashid MU, Sarin R, Teo SH. Current Status of the Management of Hereditary Breast and Ovarian Cancer in Asia: First Report by the Asian BRCA Consortium. Public Health Genomics. 2016; 19: 53-60. https://doi. org/10.1159/000441714. 